\title{
Challenges Faced by Older Adults With Cognitive Impairment and Their Caregivers in a Care Home
}

\author{
Yaw Frimpong \\ Jiangsu University, School of Management, Department of Health Policy and Management \\ 301 Xuefu Road, Zhenjiang, 212013, P.R. China \\ E-mail: frimpong13@hotmail.com \\ Dai Baozhen (Correspondent Author) \\ Jiangsu University, School of Management, Department of Health Policy and Management \\ 301 Xuefu Road, Zhenjiang, 212013, P.R. China \\ E-mail: hixiaodai@126.com
}

\begin{abstract}
Bernard Sarpong
Centre for Disability and Rehabilitation Studies, Department of Community Health, Kwame Nkrumah University of Science and Technology, Kumasi, Ghana E-mail: besarpong2@gmail.com
\end{abstract}

Received: April 11, 2019 Accepted: June 2, 2019 Published: June 4, 2019 doi:10.5296/ijsw.v6i1.14655 URL: https://doi.org/10.5296/ijsw.v6i1.14655

\begin{abstract}
This study examined the challenges faced by older adults with cognitive impairment and their caregivers in Kumasi Cheshire Home (Ghana). In-depth semi-structured interviews were conducted with 50 older adults with cognitive impairment and 9 professionals (caregivers). The findings of the study indicated that older adults in care homes are likely to face social inclusion difficulties, and institutional abuse in the form of being forced to eat or go to bed at a particular time, and medication difficulties since it takes quite a long time for the drugs to arrive in the care home. It also found out that the challenges professionals (caregivers) face include: financial difficulties, extreme pressure at work, among others. Lastly, it was again
\end{abstract}


revealed that caregivers in the care home used spirituality as a coping strategy. Recommendations were made to assist in future research in the area and provide a strategic plan to improve the condition of adult healthcare for individuals with cognitive impairment

Keywords: Cognition, Cognitive impairment, Mental health, Inmates, Caregivers

\section{Introduction}

The predominance of age-related health issues is turning into a vital public health concern as proportions of older people in populations worldwide develop. Projections show that with the dynamic aging of the population, the predominance of cognitive impairment, Alzheimer's disease, and other dementias are anticipated to extend within the coming years. (Hebert, Scherr, Bienias, Bennett, \& Evans, 2003)

Cognition involves multiple domains comprising attention (focusing, shifting, dividing, or sustaining attention on a particular stimulus or task), executive function (planning, organizing thoughts, inhibition, control), visuospatial ability (visual search, drawing, construction), memory (recall and recognition of visual and verbal information), and language (expressive and receptive) (Cumming, Brodtmann, Darby, \& Bernhardt, 2014).

Cognitive Impairment is a major health problem in old age. It is a major cause of disability and may result in an inability to care for oneself at the oldest ages. Interest is focused on cognitive impairment because it diminishes the standard of the lifetime of each the individual with the condition and the relation. Langa et al. (2001) also added that cognitive impairment is additionally one of the main causes of institutionalization, and a significant proportion of health care resources are spent caring for older adults with this condition

Cognitive impairment and dementia are expanding all-inclusive and are anticipated to extend proportionately more in developing countries. (Mathers \& Loncar, 2005). It is estimated that by 2050 the number of individuals older than 60 years will be approximately 2 billion and will account for $22 \%$ of the world's population. Four-fifths of the people older than 60 years will be living in developing countries in Africa, Asia or another geographical region. (Bongaarts, 2009). Garrett (1999) affirmed that these developing countries, as well as those in sub-Sahara Africa, are undergoing a demographic and epidemiological transition and therefore the impact of population aging in these regions can increasingly augment the burden of noninfectious and chronic diseases in this region

Care homes are known and believed to play an important role in promoting the quality of life of its patients and individuals with cognitive impairment are of no exception. Globally, the population is ageing and the demand for health and home care services has become vital (Frimpong, 2015). Despite the fact that care homes are promoting the quality of life of persons with disabilities, there are several challenges bedevil care homes generally. Critical among them is financial difficulties. Most care homes are faced with non-availability of sufficient funds to run and provide quality service to its inmates. These financial constraints also tend to make care home services inaccessible to those who need such services. Although some reimbursement for the provision of services or some cash benefits exists in most of the European countries, a number of economic factors restrict affordability and consequently access to home care in many countries (Amano, 2019)

Caregiving refers to the category of activities of daily living (ADLs), (for example, personal 
grooming, bathing, dressing, feeding, transfers etc.) and instrumental activities of daily living (IADLs) (for example, preparing meals, and housework) (Nancy Guberman, Lavoie, Blein, \& Olazabal, 2012). Professionals parents, relatives and close friends of older adults with cognitive impairment perform the roles mentioned above in one way or the other. The general importance of caregiving is emphasized in the quote by Carter (2012). Carter (2012) said that, people in this world can be classified into those who were once caregivers; those who are caregivers now; individuals who will be caregivers in the future; and those who will be in dire need of caregivers. This assertion hints of the fact that at any point in time, it is either one is a caregiver, or one needs a caregiver.

Research has proven that quality caregiving promotes the psychological, emotional, physical and social wellbeing of care recipients (Guberman, 2010). Thus, when older adults with cognitive impairment get quality health care, they can interact well with peers or relatives; they are able to participate in daily life activities; they enjoy good health, and they are able to socialize with other persons without feeling stigmatized.

Although caregiving is an important area to consider, caregivers of older adults with cognitive impairment face a lot of challenges which affect them negatively. Examples of these challenges include frustration, depression, emotional strain, boredom, low morale, sadness, stigma and feeling of helplessness (Clancy et al., 2019). Moreover, Philp et al. (1995) stated that caring for an individual with cognitive disability results in higher levels of stress and loneliness on the side of caregivers than caring for individuals with other forms of disability. Most caregivers of older adults with cognitive impairment in Ghana abandoned their patients due to congestion in the psychiatric hospitals and nursing homes, it could be said that they encounter a lot of challenges (Tawiah, Adongo, \& Aikins, 2015)

The negative impact of the challenges on caregivers can lead to lapses in their roles (Whitlatch, Zarit, \& von Eye, 1991) However, their (caregivers') role in ensuring that older adults with cognitive impairment get quality health care is significant. Therefore, there is a need for stakeholders to adopt strategies to support and build the capacity of caregivers, so that they would be able to overcome the cluster of challenges that confront them. Forducey, Glueckauf, Bergquist, Maheu, and Yutsis (2012) recommended that providing information, financial support, encouraging respite care and organizing training programmes for caregivers equip them to render quality health care. Also, support services help to boost the capacity of caregivers in dealing with challenges associated with their roles.

Research, policy, and advocacy addressing the needs of older adults with cognitive impairment caused by Alzheimer's disease and their caregivers are as fragmented as the health care industry that seeks to provide care for these vulnerable elders (G. A. Sachs, Shega, \& Cox-Hayley, 2004). With the logical advent of interest in prevention and earlier recognition of cognitive impairment, dementia, the size of the population of older adults in potential need of care for impaired cognition has significantly expanded (Petersen \& Morris, 2005)

Cognitive impairment in Ghana has become an increasing cause of stigmatization and discrimination due to changes in lifestyle and an emerging aging population. Whilst the public sector has an important role in promoting health and well-being, supporting self-care and preventing ill-health, it is recognized that there are many other private organizations 
particularly in the voluntary, community and independent sector, which may be better placed to provide these services (Frimpong, 2015) as one of the significant efforts to promoting home care services. According to Van der Geest (2002), in Ghana, however, formally organized professional care for the elderly is minimal. The only facilities available in Accra and perhaps a few other places are daycare centers where elderly people can meet each other, pass time with games and other activities.

However, research studies on the subject are still in a nascent stage, hence the need for this paper. Findings from this study will, therefore, make recommendations that will be valuable for future researches on cognitive impairment, its related challenges and the quality of life of individuals with the condition. This will be a valuable enhancement to literature since this study will provide additional data on Ghanaian patients with cognitive impairment. Specifically, the paper seeks to address the challenges faced by older adults with cognitive impairment and their caregivers in a care home. It also seeks to examine the coping strategies adopted by caregivers in care homes.

\section{Materials and Method}

The paper adopted a qualitative approach and descriptive exploratory design on the challenges faced by older adults with cognitive impairment and their caregivers in Kumasi Cheshire Home and the coping strategies adopted by caregivers to overcome such problems. The study relied on in-depth semi structured interviews with surveys of experiences of patients and their caregivers in Kumasi Cheshire Home, and grounded theory was used to reveal common themes derived from the data itself (Glaser \& Strauss, 1967). The grounded theory operates virtually in a reverse fashion from traditional social science analysis. The primary step for the grounded theory is to collect information through a spread of methods. The key points are marked with a series of codes extracted from the information collected. Then, the codes are classified into similar ideas and categories are formed from these ideas. Grounded theory, that has been a classic and still standard technique for analyzing health information and aims to conceptualize what is happening by using empirical research, is useful to explain the similarities among persons with particular experiences

\subsection{The Study Settings}

The research was conducted in the Kumasi Cheshire Home (Ghana), a non-profit making and non-governmental organization established by Catholic Archbishop Emeritus Dr. Peter Kwesi Sarpong with the support of some concerned citizens and other church leaders in 1986. The home seeks to rehabilitate discharged individuals with cognitive impairment in Ghana, for effective reintegration into communities safe and sound. The care home undertakes continuous medication, occupational therapy, guidance and counseling, religious activities and aftercare services. The main source of funds for this home is from donations from philanthropic organization and individuals and token fees paid by parents or guardians of service users. The Ghana Health Service also sometimes provides free medications and nurses to assist in the caregiving activities of the home. The Kumasi Cheshire Home was chosen for this study because it had well organized managerial and operational structures to allow for easy data collection. 


\subsection{Population and Sample}

The population of interest (sample) was recruited particularly from the Kumasi Cheshire Home which was established to rehabilitate and integrate adult psychiatric patients back into society. The primary population comprised fifty (50) in-patients out of sixty-five (65) randomly selected males and females. The purposive sampling method was used to select case samples because the sample was based on who could provide relevant information about the study. Also, nine (9) out of thirteen (13) caregivers at the Kumasi Cheshire Home were selected to be interviewed on their challenges in executing their duties.

\subsection{Data Collection and Instrument}

Face-to-face interviews were conducted with the respondents on the challenges they faced in the care home. The test parameters included feeding, accommodation, medication, the quality with which personnel offer services to them, social inclusion, and so on. In-depth interviews were held using an interview guide to collect information from the caregivers (professionals) and also challenges that they encounter in their daily lives in the care home. Individuals present during a single interview included one researcher (interviewer), one participant and one research assistant (to take notes). Each interview began with a broad data-generating question: "Please tell me the challenges you face in the care home?" After that, additional questions were asked to further know the specific challenges faced by caregivers in the care home. Example probes were "Do you receive any periodic training?" "Do you get any financial support from the government?" and so on. All participants were interviewed separately except for one person who wanted the relative present as a support during the interview. The interviews lasted between 40 and 60 minutes and all participants were able to express themselves and were willing to share their stories. An audio- recorder was also used during the discussions. The research questions were shaped by the explanatory model (Kleinman, 1980). A pilot study was conducted in one care home called (Comfort for the Aged) in Accra, Ghana prior to the actual study. Interviews for the patients were conducted in the local dialect which is the Twi language while the English language was used to interview the caregivers (professionals)

\subsection{Data Analysis}

The audio-recordings in English were transcribed verbatim by the researchers, while the recordings in the Twi Language were given to experts of Modern Languages, to be converted to English transcripts. For accuracy, the transcriptions were compared again with the notes the research assistant took during the interviews at the study sites. All the transcripts were then given to two coders who had been trained for grounded theory and opening coding independently coded the translations for themes, subthemes, and categories. Open coding that is conceptualizing on the first level of abstraction (Strauss \& Corbin, 1997) was conducted by two coders with line by- line coding. The codes were checked by the first author to ensure the validity of the interview coding. Discrepancies in coding were resolved by discussion among the coders. After the consensus of the codes was obtained, the codes were put into categories, from which the themes and subthemes were extracted. Extra readers were invited to help resolve any differences between the researchers' summaries.

\subsection{Ethical Considerations}

Ethical approval was obtained from the Department of Health Policy and Management, Jiangsu 
University and administrators and authorities of the Kumasi Cheshire Home. The respondents were told that their participation was voluntary and they can withdraw from the interview whenever they wish to do so. They were also assured the information given was highly confidential without using names or any familiar description and was solely for academic purposes.

\section{Results}

\subsection{Demographics of Respondents}

Table 1. Characteristics of in-depth interview adults with cognitive impairment

\begin{tabular}{llll}
\hline & & Frequency $\mathbf{( N = 5 0 )}$ & Percentage (\%) \\
\hline Gender & Male & 19 & 38 \\
Total & Female & 31 & 62 \\
& & $\mathbf{5 0}$ & $\mathbf{1 0 0}$ \\
Age group & 40 years and below & 3 & 6 \\
& 41 to 50 years & 6 & 12 \\
& 51 to 59 years & 9 & 18 \\
Total & 60 years and above & 32 & 64 \\
& & $\mathbf{5 0}$ & $\mathbf{1 0 0}$ \\
Marital status & Married & 18 & 36 \\
& Divorced & 21 & 42 \\
Total & Unmarried & 11 & 22 \\
Educational status & Middle school & $\mathbf{5 0}$ & $\mathbf{1 0 0}$ \\
& Senior High School & 12 & 62 \\
Total & Tertiary & $\mathbf{7}$ & 25 \\
Diagnosis of patients & Mild cognitive impairment & 26 & 13 \\
& Alzheimer's disease & 24 & $\mathbf{1 0 0}$ \\
& & $\mathbf{5 0}$ & 52 \\
& & $\mathbf{5 0}$ & 48 \\
& & $\mathbf{1 0 0}$
\end{tabular}

Data from the study area (Kumasi Cheshire Home) indicated that a high proportion of the respondents (adult with cognitive impairment), of $62 \%$ were females whereas $38 \%$ were males. Also, most of the respondents (32) were 60 years and above representing $64 \%$ of patients who were 40 years and below is the lowest proportion with 3 respondents, representing $6 \%$. The next higher proportion of the respondents by age was those within the year range of 51 to 59 
years of age with $18 \%$. Adult care patients who were between 41 to 50 years of age were 6 , representing $12 \%$. The minimum age is 37 and a maximum 64 with an average of 50.5. On marital status, 18 of the patients were married, 21 were divorced and 11 were single. The demographics of the respondents are represented in the table above.

Table 2. Characteristics of in-depth interview caregivers (professionals)

\begin{tabular}{llll}
\hline \multirow{2}{*}{ Gender } & & Frequency (N=9) & Percentage (\%) \\
& Male & 5 & 55 \\
& Female & 4 & 45 \\
& 30-39 years & 3 & 33.3 \\
& 40-49 years & 4 & 44.5 \\
Educational status & 50-59 years & 2 & 22.2 \\
& Middle school & 2 & 22.2 \\
& Senior High School & 3 & 33.3 \\
Work Experience & Tertiary & 4 & 44.5 \\
& 3-5 years & 7 & 78 \\
& 6years and above & 2 & 22 \\
\hline
\end{tabular}

\subsection{Thematic Analysis}

Three main themes emerged, including: challenges faced by older adults with cognitive decline, challenges faced by caregivers and coping strategies adopted by caregivers to overcome such challenges in the home. Sub-themes were identified under each of the main themes.

Table 3. Summary of the themes and subthemes

\begin{tabular}{ll}
\hline Themes & Sub-themes \\
\hline Challenges faced by older adults in the care & a) Feeding \\
home & b) Accommodation \\
& c) Medication \\
d) delivery of service & e) lack of social inclusion \\
& f) use of derogatory terms \\
challenges faced by caregivers in the care & a) Financial constraints \\
home & b) Extreme Pressure at work \\
& c) Neglect \\
d) Minimal training on the part of the
\end{tabular}


Coping strategies adopted by caregivers

caregivers

a) spirituality as a coping strategy

b) Acquiring enough knowledge

c) Staff members work as a team

\subsection{Challenges Faced by Older Adults with Cognitive Impairment in the Care Home} Feeding

According to the findings from the adult caregivers in the research area, food is the highlight of the day for many of the adult patients in the home and is a measure of the overall quality of the service rendered to them. Even though the selected respondents complained that their food was either small or taken in late hours, there was no form of challenges in feeding them as the caregivers fed them equally and with the needed attention. One of the patients remarked:

"Since I was admitted to this home, food is shared equally among us even though sometimes they are served in late hours. So I depend on the little provisions (milo, sugar, bread) I have in my locker which was provided by my daughter".

Another respondent also reiterated that they get donations in a form of food items from nongovernmental organizations and philanthropists which is not enough for them. This was what he said:

"We get donations in a form offood items from organizations and philanthropists during festive seasons like Christmas, Easter and Eid Ul Adha. After these festive seasons hardly do we get donations so we make sure we save some of the food. However, it does not take a long time before the food items get exhausted because we depend heavenly on them."

Getting the right kind of food to eat sometimes becomes difficult for inmates at the home. According to most of the respondents they do not have enough funds to cater for themselves because they are not working. They rely solely on the home and outsiders. This makes it difficult for them to get the right kind of food to eat. One of the respondents remarked;

"Am not working, as a result, I depend solely on the home and sometimes my relatives and this puts me in a position where I have no choice but to accept whatever meal that am being given. I kind of dislike most the food that is being given but I have to accept it because I have no other choice.

\section{Accommodation}

It was realized that some of the inmates (patients) were kept in a well-ventilated room with a bed made of wood whereas others were in other rooms where they laid beds on the floor with either bed sheets or old mattresses. The explanation given was that bedding fee was being charged to be paid by the patients' family and for those who were neglected by their families; they faced the challenge of being kept in a poorly managed room. A 52-year old married patient at the Kumasi Cheshire gave this account;

"I was neglected by my wife and children after a month of being admitted into the home. I am being fed every day and given medication as well but because my family is not available to pay for the required accommodation fee, I sleep on an old bed sheet laid on the floor. I do not feel 
comfortable sleeping in that condition and it is even worse during the cold weather and I think I'm being discriminated in the home"

Also, some of the respondents were of the view that the fans in their rooms were either spoilt or have been taken away and because of this the room temperature sometimes becomes hot and unbearable. Some of them also revealed that they need more buildings to accommodate them. This was the comment from one of the respondents:

"I don't like to sleep in a hot room but here I have no option than to accept whatever comes my way. Sometimes when the weather is cold, I feel very comfortable sleeping in the room however when the weather becomes hot, it becomes unbearable to sleep in the room. I would like to appeal to the government and other rich people to come to our aid."

Another of the respondents was also of the view that when the bulbs in their rooms become dead, it takes longer for them to be replaced. He said that this makes them feel uncomfortable sleeping in the room. This was what he said:

"I don't like to sleep in darkness so I manage to use the torch in my phone as a source of light when the bulb in my room is dead and it has not been replaced. But there are others who neither have a phone nor a torch so they borrow from me. However, it is not always I give it to them because I might be using it."

The respondents gave very good remarks concerning the availability of water and proper washroom where they can ease themselves and wash down. These are a few of the comments from the respondents:

"We have a bath house here and we also have a toilet here. This makes life easy for us. There is also water here which we use to bath and wash down. I think we are very lucky to have this basic necessity available"

"Yes! Of course, there is water here. We can get water at any point in time and this makes life very easy for us. The only problem that we used to have concerning water was when the pipes were not flowing but the authorities have been able to solve by buying water tanks to store water. This has made water available at any point in time."

"We have washrooms here and this is very good. But my problem is sometimes the washroom is left uncleaned and this makes the place very smelly. Those clean do it in the morning and come back to clean it the next morning. Supposing the place become dirty in the afternoon, we would have to wait till the next day for the place to be clean."

\section{Medication}

The medication for adults living with cognitive impairment in the study area was provided by the Ghana Health service and therefore individuals were duly administered with their required drugs at the right dosage. The challenge was with procurement as it took quite a long time for these drugs to arrive in the home to be given to the patients. For instance, a caregiver remarked: "The patients here are given medications as it is required of us. We make sure that they take the drugs which we have administered to them by supervising them ourselves because some of them don't like to take the drugs. Our being here would be a waste of our time if we don't supervise them to take the drugs. I have been working here for some time now and I have seen a significant improvement in the recovery of inmates as compared to when they were kept in their respective homes. I must say the government is doing well when it comes to supplying the 
homes with medicines for the inmates.

\section{Delivery of Service}

On the caregivers' attitude to service delivery, most of the respondents (patients) did not like the way they were being treated by the caregivers. These unfair treatments were seen in the changing of their clothes when they eased themselves or when as a result of certain ailment they needed assistance to move part or whole of their body. These were the comments of some of the patients:

"My family has abandoned me and I get no one to visit me regularly, the house helpers feel reluctant to help me when I am in need since they do not get any money from my relatives."

"They treat me with disgust because sometimes I become restless and unconscious of my surroundings. I even ease on myself at times and I become embarrassed after this episode. "For the caregivers, they are good but at times they become furious with me and their attitude towards me depicts that they are fed up with me. I want them to be patient with me and treat me well even when I behave badly."

On the contrary, it was observed that other inmates are being treated very well since the house helpers get a lot of gifts and money from their relatives. One of the response was of the view that:

"I am warmly treated by the caregivers. They provide me with the necessary services required of them. My relatives visit me every month and they come with loads of items which I give some to my caregivers as a token of appreciation to them. I thank God for the lives of the caregivers because they have made my stay here very pleasant."

\section{Lack of Social Inclusion}

The respondents in the Kumasi Cheshire Home admitted that they were being neglected by their family and friends and therefore they felt not belonged to the society. They further complain of lack of stimulation, activity, opportunities for social interaction, including sexual relationships, and community participation. They also claimed that they felt more abused as they are being compelled under harsh conditions to eat, sleep or undertake certain activities. One of the respondents gave an as an account of his ordeal;

"I was abandoned in the early stages of my life when I was affected by the condition. I lived on the streets and fed on residues in the markets and refuse damp. As I aged on, I became weaker and weaker and I could not go out to get even the feed drops. A market woman suggested me to this home and they came to get me to live here. I always get worried when I always remember my family but I do not want to go home again. My family members feel ashamed to live with me."

However, the study revealed that the only social activity for the patients was with their fellow inmates but to the outside individuals, they were ignored because they do not partake in any mainstream activities.

Use of Derogatory terms for Cognitively Impaired People

Several derogatory terms were identified in this study including 'idiot', 'imbecile', 'mental incapacity' 'madness', 'insane', and 'abodam'

In this study, most participants referred to cognitively impaired people by the Ghanaian term 
“abodam". Caregivers and patients were particularly concerned when people referred to cognitive impairment using the same terminology, as "abodam" seemed to arouse more intense concern among the majority of the participants than the illness of cognitive impairment itself. One of the caregivers asserted:

"I feel that the terminology abodam is bad, and to some extent it involves discrimination and it's a big challenge for me to overcome such

Another caregiver specifically remarked:

"The myth and belief surrounding mental disorder in developing countries like Ghana gives a negative cultural perception and this leads to a high level of stigmatization"

Challenges faced by caregivers in care homes

The findings, with respect to the challenges listed by the caregivers, the most pressing challenge was financial difficulties, extreme pressure at work, substandard facilities and equipment to carry out duties, neglect of patients by family members after treatment, inadequate training to carry out extra challenges that may arise in duty dispensation and inadequate recognition and compensation for work done.

\section{Financial difficulties}

Most of the respondents revealed that the home is faced with non-availability of funds to run and provide quality service to its inmates. These financial constraints also make the care home services inaccessible to those who need such services. Although some refund for the provision of services or some cash benefits is available in most of the European countries, a number of economic factors restrict affordability and consequently access to home care in many developing countries like Ghana. Many of the caregivers asserted that the care home is supported financially by philanthropists and individuals who deem it a need to help fund home care activities. In most cases, relatives do not pay for the services of the people admitted here or even when they are made to pay, the amount is very minimal. Some of the respondents revealed that:

"The support from the government is not encouraging at all. The funds for running the school either come in late or do not come at all. As you know the inmates here depend solely on the home for their daily needs. We find it very difficult to run the home because the fund available is very minimal."

Another caregiver interviewed also was of the view that:

"Sometimes I even use my own money to cater for the inmates. You know we cannot depend on the government and other people for our needs all the time. What I do is save some money and use to buy the necessary teaching and learning materials which I may need during classes hours."

It was realized that most of the caregivers were negatively affected by the non-availability of funds in the home, since most of them sometimes support the patients in the care home with their own salaries and other sources of income. They see it as a big challenge for them in working in the home.

Extreme pressure at work

During the interview, most of the respondents revealed that their work is very demanding and 
as a result, they are always feeling tired. Moreover, they (caregivers) had no option than to take up roles outside their duties because of their limited number. This leads to too much pressure at work which makes the adult care home labor intensive and makes it difficult to procure competent workers in sufficient numbers to match the growing demand for the adult home care services. One of the respondents asserted that:

".......the number of patients in the care home keeps on increasing. We used to have just thirty-five (35) patients but as it stands now, we have over fifty (50). I sometimes suggest to the administrator about giving us the caregivers' opportunity to work together without running a shift."

Similarly, another caregiver remarked:

"Caring for the inmates is more laborious than caring for "normal" people. The training we received is different from the job itself. Because of their mental status, you would need to watch them more often than not lest they cause themselves harm."

Neglect

The Kumasi Cheshire Home has the only 62 -bed capacity and a large room for others whose relatives do not pay for their accommodation. The rehabilitation programmes range from a minimum of 9 months to a maximum of 18 months. Nevertheless, the study revealed that due to family members neglecting their relatives who are in the home, the home is compelled to continuously house the patients even when they are fit to live in the outside society. A senior caregiver reported this;

"The oldest patient, a 66-year old man has lived in the center for about ten (10) years and sometimes helps in carrying some chores in the home. She explained that the man was abandoned by his family members a few months after he was admitted and the center could not trace any relative when his rehabilitation period was successful and over. Some of the patients who are also in that condition are sometimes employed as house helps to help their daily upkeeps."

\section{Minimal training on the parts of the caregivers}

From the research, it was revealed that most care homes staffs, as well as Kumasi Cheshire home, often receive minimal training in line with statutory requirements. This is related to the lack of investment in staff which is likely to be costly in the long run due to increased turnover and recruitment costs. It is also revealed that when staffs are trained individually by being sent on a course, they find it hard to change their practice on returning to work because of culture, environment, and peer pressure. Moreover, from the respondents, it was revealed that less training leads mostly to underperformance on the part of the caregiver as they are faced with additional situations outside their jurisdiction of work which might also need attention.

Also, all the caregivers stressed that they need periodic training in order to be updated about modern trends in caregiving. They added that relying on their experience and observation alone was not the best way to render quality care to the patients. Some of the respondents said:

"We learn from experience. That is, we observe the patients know the patient's behavior in order to know how to cope and handle him or her and this is not good enough. We need periodic training and advanced knowledge and skills to be able to cater to the patients effectively" 
"It is very necessary to be trained in order to render quality service to the patients"

Coping strategies by caregivers

According to the study, the coping strategies adopted by caregivers to handle the challenges that go with caring for persons with mental illness in diverse ways such as spirituality, acquiring enough knowledge about the disease and getting support.

Spirituality as a coping strategy

According to the majority of the respondents, the spirituality attached to their work is highly a source of inspiration for them. Most of them revealed that they are doing this type of work because they believe strongly that one day God will reward their effort. Some also revealed that in caring for the inmates, they are able to discharge a lot of negative energies posed by life because they believe by doing this work God will take care of their needs. Some also asserted that doing work such as this is similar to doing the work of God. One of the respondents said that:

"I have worked here for many years and I think God Almighty will bless me because I'm doing something that a lot of people will not do. Some relatives of some of the inmates do not even want to visit them let alone cater to them. So I believe I'm standing in the gap which means that I'm doing the work which is expected of me by God."

Another respondent also revealed that:

"There is a saying in the Bible that goes, do unto others as you want them to do onto you. I know I'm doing the right thing. I believe I will reap what I'm sowing or my children are the ones who will benefit from what I'm doing now."

Acquiring Enough Knowledge

As revealed by the respondents getting to know more about the mental illness disease, they would be in a position to know the challenges that come with mental illness and also get some information about how to handle the challenges. A respondent asserted that:

"As I carry on with my duties, I come across new challenges every day and this compels me to learn more about the disease so that I can resolve the challenges that come my way."

Another caregiver was of the view that learning on the job comes naturally as he tries to overcome difficulties thrown at him by the job. This was his comment:

"When I started this work I never thought I could overcome some of the challenges but here I am today! I have device my own way to solve the problem I encounter based on my experience here. For example, I have managed to find ways to raise money for the home through selling some of the products made by the inmates to buyers and the income is being used to cater for some basic needs of the home."

Staff members work as a team

From the research, it was revealed that most of the caregivers work as a group because of their number. Most of them were of the view that because they have stayed together in the house for some time now, they live like a family now. So they support each other their duties, one of the respondents commented that:

"Because of the nature of our work, we have developed a passion for our work and because of that we helped each with duties should in case they need any form of assistance." 


\section{Discussions}

As it is well known older people will encounter some functional declines as their age increases, and nothing can stop this natural process. Studies have made it relevance to focus on long term care for older adults with cognitive impairment, and other dementias since most of these syndromes are incurable, progressive, debilitating, and ultimately terminal conditions. (G. Sachs, 1998). In this study, the researcher focused on adults with cognitive impairment living in a care home. Care homes are known and believed to play an important role in promoting the quality of life of its patients and older people with cognitive impairment are of no exception. Older people living in care homes are often frail, and they are one of the most vulnerable groups in society. (Alldred, Kennedy, Hughes, Chen, \& Miller, 2016) .

\subsection{Challenges Faced by Older Adults in a Care Home}

The respondents revealed that living at the care home has its own challenges. They were specific to the aspects as follows: feeding, accommodation, medication, delivery of service and social inclusion.

The respondents asserted that with regards to feeding there was no form of challenges. They also revealed that government supply with regards to feeding was insufficient and as a result, they rely on donations from NGO, s, churches, and philanthropists. This goes contrary to the report from the World Health Organization (2012) which revealed that care homes need financial support to be able to provide appropriate care for a long period of time. Without donations from people, the home cannot be run.

Accommodation plays a very important role in caring for patients in a care home. The respondents revealed that boarding fee was charged to be paid by relatives of inmates and for those who could not pay were kept in a poorly managed room. Unfortunately, there were insufficient buildings to accommodate inmates. Therefore, there is a need for the government to build more houses in the home to accommodate the inmates. For the inmates to recover early, medication plays a very crucial role. The qualitative findings reviewed that the home provides the inmates with medication. However, it takes a longer time for the drugs to arrive. Inmates need to take their medications on time in order for their condition to become better.

In essence, the study shows that any time the inmates eased on themselves or due to sickness they need help to move about but it was realized that that preferential treatment was given to those whose relatives are generous to the caregivers. However, the American Psychiatric Association (2013) revealed in their report about persons with disabilities that persons with disabilities have affected adaptive functioning in social judgment learning, self-direction, communication, personal care, memory, self-management, and home care and finds it difficult to perform their daily living activities. As such, caregivers must regularly and effectively care for their disabled persons so as to help improve their whole wellbeing, as Enoch, Mprah, Owusu, and Bediako (2017) suggested that quality caregiving has the tendency to improve the emotional, physical, spiritual, mental, and social health of the disabled person.

It is a pity that most of the inmates are neglected by their families because of their condition. However, Hardman (2000) proposed that it is advisable for relatives to collaborate with caregivers by visiting their disabled relatives and interacting regularly with them to examine 
their performance. Moreover, they also added that at times they were forced to eat or sleep which is an infringement upon their right. According to Zarkowska and Clements (2018), caregivers need special training for this task and therefore are encouraged to desist from this kind of approach. Finally, it was revealed from the study that inmates were ignored in participating in mainstream activities which goes contrary to the works of Milner and Kelly (2009) which revealed that, a person with disabilities should be included in community participation and mainstream activities regardless their impairment.

\subsection{Challenges Faced by the Caregivers in the Care Home}

Research studies on care homes in Africa and therefore Ghana are very minimal. A study by Muwaniki (2013) in South Africa revealed that challenges care homes in Africa are not different from those pertaining to those in the western world. The researcher found out that care homes in South Africa are confronted with challenges such as lack of practical skills to provide effective home based care, limited financial support and stigmatization. Also, Action found out that home-based care in Sub-Sahara Africa is faced with the following challenges in the dispensation of their duties; lack of regular training and supervision, supervision and lack of psychological support. In a study of challenges faced by care homes, The RCN (2011) found out that ten common challenges facing care homes included funding and admissions, staffing level, appropriate skill mix, recruitment and retention, low levels of moral and extreme pressure at work, lack of training, lack of equipment, inspections and bureaucracy, the ethic of the care home and concerns about the general management and difficulties working with professionals from other sectors.

Most care homes in Ghana, like the study area (Kumasi Cheshire Home), are faced with non-availability of funds to run and provide quality service to its inmates. These financial constraints also make care home services inaccessible to those who need such services. (Devereux, 1993). According to Muwaniki (2013), although some reimbursement for the provision of services or some cash benefits exists in most of the European countries, a number of economic factors restrict affordability and consequently access to home care in many developing countries like Ghana. Funding is very important in running an institution in every part of the world. Unfortunately, there was not enough funding for the home. Caregivers revealed that the lack of funding has made them unable to meet the demands of their work because they are unable to acquire the necessary items for their work. However, Donelan et al. (2002) reported that caregivers require financial support in order to provide suitable care for a longer time.

From the comments made by the respondents, it looks like they are overwhelmed by the demand for their work. They revealed that their work is very demanding and as a result, they are always feeling tired. Moreover, caregivers had no option than to take up roles outside their duties because of their limited number. This is not encouraging because many roles could lead to tiredness, stress and a lack of interest in the work on the part of the caregivers. This is line with the works of Biegel, Sales, and Schulz (1991), Cranswick (1997) and N Guberman (2010), which revealed that the challenges of stress, frustration and exhaustion may be due to the fact that the caregivers either lack or have little knowledge about how to care for the inmates.

Adequate training is an important aspect of every work. However, the research revealed that 
there was a lack of investment in the staff. Caregivers revealed that they lack adequate knowledge and training with regards to their work which lead to underperformance at work. This is confirmed by the work of Schumacher, Stewart, and Archbold (1998) which revealed that it is necessary that all caregivers should acquire enough knowledge and skills so as to be in a position to render quality care. Smith (1999) added that caregivers should be trained adequately with regards to competence to be able to deliver quality care.

\subsection{Coping Strategies Adopted by Caregivers in the Care Home}

Nevertheless, of the challenges, the caregivers were still working because of the love they have for it, as American Society of Clinical Oncology (2015) proposed that the rewarding aspects of caregiving should be focused on by caregivers rather than the challenges that are attached.

The following coping strategies were adopted by caregivers as a result of the challenges they faced: spirituality as a coping strategy, acquiring enough knowledge, financial support from NGO's and staff members working as a team.

Spirituality is recognized as a significant feature of Ghanaians (Okraku, Ofori-Atta, Danquah, Ekem, \& Acquaye, 2009) and the African American way of life (Mattis \& Jagers, 2001). According to Bediako and Neblett $\operatorname{Jr}$ (2011), spirituality takes on an appreciative awareness of the continued presence of ancestors, prayers or requests for assistance form a higher power, and respect for the presence of "spirit" in others

As noted from the results of this study, caregivers face of the numerous challenges, they are still doing the work because they believe that in as much as they are taking care of the inmates, God will reward them one day. They made many references from the Bible and Quran about how some people were blessed by God from their good works towards their neighbor. The findings also reveal how caregivers in collective cultures express the psychological distresses in a somatic form and not expressing it in terms of emotions.

Also, religion and the belief in deities also account for these relationships. Research has shown that in addition to social support, patients may use spirituality as a resource to facilitate emotional adjustment and resilience: they have more positive feelings and pay attention to the positive elements in their life (Anarfi, 2015)

Getting enough knowledge is very important for caregivers to effectively execute their duties at home. Caregivers were of the view that at times they meet to share ideas on their experiences for other caregivers to learn from. This is very helpful because through this method caregivers are able to learn from each other. The World Health Organization (2012) also recommended that all caregivers should be well-informed about the people they care for so that they would be in the position to either ease or manage the challenges they face.

As a result of the challenges they faced, staff members work as a team. As revealed by Dias et al. (2008) caregivers must team up with other experts in finding and making maximum use of inmates' abilities.

The negative impact of the challenges on caregivers can lead to lapses in their roles (Whitlatch et al., 1991). However, their (caregivers') role in ensuring that older adults with cognitive impairment get quality health care is significant. Therefore, there is a need for stakeholders to adopt strategies to support and build the capacity of caregivers, so that they 
would be able to overcome the cluster of challenges that confront them

\section{Conclusions}

The study sought to examine the challenges faced by older adults with cognitive impairment and their caregivers in a care home. It also ascertains the coping strategies adopted by caregivers to overcome such problems. It was revealed from the study that social inclusion which is the basics of the rehabilitation for the adults with cognitive impairment was minimal as the inmates complained of being neglected by family and friends and endured some level of abusive treatment while receiving the care.

Moreover, the financial constraint was a major challenge to the care home since the home is non-governmental and depended mainly on philanthropy. This even affected the type of accommodation offered to the inmates which in a way was a kind of challenge.

\subsection{Limitations}

The study concentrated only at Kumasi Cheshire home in the Kumasi Metropolitan area, without including other home cares in other regions of Ghana. Hence the findings may not be representative of the situation in the country and cannot be generalized. Also, the researcher was not able to get information from some of the selected patients from the care home because of their nature of the impairment.

\section{Recommendations}

The study strongly recommends that the government and relevant stakeholders must formulate proper policies to regulate the management and administration of adult care homes for people with cognitive impairment. These policies must include the setting up of funds to support the already existing adult centers, and furnishing them with the required human and material resource needed to run the home care centers.

Also, specialized programmes to develop key staff in the area of provision of specialized care and support for the aged in the society must be established by educational institutions. There should be training for specialists in Geriatrics and more psychiatrists to give the aged the special care they need.

Furthermore, creating awareness through massive public education; This is to give insight into cognitive impairment, treatment modalities, recovery, and prevention. The need for society to realize and be willing to learn that cognitive impairment and its related ailments have nothing to do with witchcraft and that it's rather a medical condition, neither does one choose it when times are tough nor is it a respecter of persons. Educating people about the attitudinal change especially towards people living with the condition and to desist from using language or words that are derogatory such as (abodam, "crazy", "lunatic",) but being friendly as a society and using less hurtful words

Lastly, promoting education, understanding, and respect will help break down barriers of ignorance, prejudice, or unfair discrimination meted out to people living with mental illness.

\section{Acknowledgement}

This work was funded by the National Nature Science Foundation of China (71774069).

\section{References}

Alldred, D. P., Kennedy, M. C., Hughes, C., Chen, T. F., \& Miller, P. (2016). Interventions to 
optimise prescribing for older people in care homes. Cochrane Database of Systematic Reviews, 2. https://doi.org/10.1002/14651858.CD009095.pub3

Amano, T. (2019). Social Engagement among Older Adults with Mild Cognitive Impairment and Conversion to Dementia. Washington University in St. Louis. https://doi.org/10.1093/geronb/gbz051

Anarfi, O. (2015). Cognitive Functioning and Quality of Life among Stroke Patients in Ghana. University of Ghana.

Association, A. P. (2013). Diagnostic and statistical manual of mental disorders (DSM-5®): American Psychiatric Pub.

Bediako, S. M., \& Neblett Jr, E. W. (2011). Optimism and perceived stress in sickle-cell disease: The role of an afrocultural social ethos. Journal of Black Psychology, 37(2), 234-253. https://doi.org/10.1177/0095798410385681

Biegel, D. E., Sales, E., \& Schulz, R. (1991). Family caregiving in chronic illness: Alzheimer's disease, cancer, heart disease, mental illness, and stroke: Sage Publications, Inc.

Bongaarts, J. (2009). Human population growth and the demographic transition. Philosophical Transactions of the Royal Society B: Biological Sciences, 364(1532), 2985-2990. https://doi.org/10.1098/rstb.2009.0137

Clancy, R. L., Fisher, G. G., Daigle, K. L., Henle, C. A., McCarthy, J., \& Fruhauf, C. A. (2019). Eldercare and Work Among Informal Caregivers: A Multidisciplinary Review and Recommendations for Future Research. Journal of Business and Psychology, 1-19. https://doi.org/10.1007/s10869-018-9612-3

Cranswick, K. (1997). Canada's caregivers: Statistics Canada.

Cumming, T. B., Brodtmann, A., Darby, D., \& Bernhardt, J. (2014). The importance of cognition to quality of life after stroke. Journal of psychosomatic research, 77(5), 374-379. https://doi.org/10.1016/j.jpsychores.2014.08.009

Devereux, S. (1993). Household responses to food insecurity in northeastern Ghana. University of Oxford.

Dias, A., Dewey, M. E., D'Souza, J., Dhume, R., Motghare, D. D., Shaji, K., ... Patel, V. (2008). The effectiveness of a home care program for supporting caregivers of persons with dementia in developing countries: A randomised controlled trial from Goa, India. PloS one, 3(6), e2333. https://doi.org/10.1371/journal.pone.0002333

Donelan, K., Hill, C. A., Hoffman, C., Scoles, K., Feldman, P. H., Levine, C., \& Gould, D. (2002). Challenged to care: Informal caregivers in a changing health system. Health Affairs, 21(4), 222-231. https://doi.org/10.1377/hlthaff.21.4.222

Enoch, A., Mprah, W. K., Owusu, I., \& Bediako, J. (2017). Role of Caregivers of Children with Intellectual Disabilities and Support Systems Available to them in Ghana. Disability, CBR \& Inclusive Development, 28(4), 80-95. https://doi.org/10.5463/dcid.v28i4.645

Forducey, P. G., Glueckauf, R. L., Bergquist, T. F., Maheu, M. M., \& Yutsis, M. (2012). Telehealth for persons with severe functional disabilities and their caregivers: Facilitating self-care management in the home setting. Psychological services, 9(2), 144. https://doi.org/10.1037/a0028112 
Frimpong, J. A. (2015). Social Support for the Aged: The Role of Private Care Homes in Accra. University of Ghana.

Garrett, M. J. (1999). Health futures: a handbook for health professionals: World Health.

Glaser, B. G., \& Strauss, A. L. (1967). The discovery ofgrounded theory: Strategies for qualitative research. Chicago: Aldire.

Guberman, N. (2010). Caregivers: Their Role in Rehabilitation. International Encyclopedia of Rehabilitation.

Guberman, N., Lavoie, J.-P., Blein, L., \& Olazabal, I. (2012). Baby boom caregivers: Care in the age of individualization. The Gerontologist, 52(2), 210-218. https://doi.org/10.1093/geront/gnr140

Hardman, C. J. D. M. L. (2000). Mental retardation: A life cycle approach: Prentice Hall.

Hebert, L. E., Scherr, P. A., Bienias, J. L., Bennett, D. A., \& Evans, D. A. (2003). Alzheimer disease in the US population: prevalence estimates using the 2000 census. Archives of neurology, 60(8), 1119-1122. https://doi.org/10.1001/archneur.60.8.1119

Kleinman, A. (1980). Patients and healers in the context of culture: An exploration of the borderland between anthropology, medicine, and psychiatry (Vol. 3): Univ of California Press.

Langa, K. M., Chernew, M. E., Kabeto, M. U., Regula Herzog, A., Beth Ofstedal, M., Willis, R. J., ... Fendrick, A. M. (2001). National estimates of the quantity and cost of informal caregiving for the elderly with dementia. Journal of general internal medicine, 16(11), 770-778. https://doi.org/10.1111/j.1525-1497.2001.10123.x

Mathers, C. D., \& Loncar, D. (2005). Updated projections of global mortality and burden of disease, 2002-2030: data sources, methods and results. Geneva: World Health Organization. https://doi.org/10.1371/journal.pmed.0030442

Mattis, J. S., \& Jagers, R. J. (2001). A relational framework for the study of religiosity and spirituality in the lives of African Americans. Journal of Community Psychology, 29(5), 519-539. https://doi.org/10.1002/jcop.1034

Milner, P., \& Kelly, B. (2009). Community participation and inclusion: People with disabilities defining their place. Disability \& Society, 24(1), 47-62. https://doi.org/10.1080/09687590802535410

Muwaniki, C. (2013). Challenges and opportunities in home based care and training in resource limited settings. Asian Journal of Social Sciences \& Humanities, 2(3), 395-400.

Okraku, O., Ofori-Atta, A., Danquah, S., Ekem, I., \& Acquaye, J. (2009). The effects of knowledge and health beliefs on coping amongst adult sickle cell patients. Ghana International Journal of Mental Health, 1(1), 87-105.

Organization, W. H. (2012). Supporting informal caregivers of people living with dementia:

Alzheimer's Disease International.

Petersen, R. C., \& Morris, J. C. (2005). Mild cognitive impairment as a clinical entity and treatment target. Archives of neurology, 62(7), 1160-1163. doi:10.1001/archneur.62.7.1160 Philp, I., McKee, K., Meldrum, P., Ballinger, B., Gilhooly, M., Gordon, D., . . . Whittick, J. (1995). Community care for demented and non-demented elderly people: a comparison study 


\section{Macrothink}

International Journal of Social Work

ISSN 2332-7278

2019, Vol. 6, No. 1

of financial burden, service use, and unmet needs in family supporters. Bmj, 310(6993), 1503-1506. https://doi.org/10.1136/bmj.310.6993.1503

Sachs, G. (1998). Informed consent for research on human subjects with dementia. AGS ethics committee. Journal of the American Geriatrics Society, 46(10), 1308-1310. https://doi.org/10.1111/j.1532-5415.1998.tb04551.x

Sachs, G. A., Shega, J. W., \& Cox-Hayley, D. (2004). Barriers to excellent end-of-life care for patients with dementia. Journal of general internal medicine, 19(10), 1057-1063. https://doi.org/10.1111/j.1525-1497.2004.30329.x

Schumacher, K. L., Stewart, B. J., \& Archbold, P. G. (1998). Conceptualization and measurement of doing family caregiving well. Image: The Journal of Nursing Scholarship, 30(1), 63-70. https://doi.org/10.1111/j.1547-5069.1998.tb01238.x

Smith, C. E. (1999). Caregiving effectiveness in families managing complex technology at home: Replication of a model. Nursing Research, 48(3), 120-128. https://doi.org/10.1097/00006199-199905000-00002

Strauss, A., \& Corbin, J. M. (1997). Grounded theory in practice: Sage.

Tawiah, P., Adongo, P., \& Aikins, M. (2015). Mental health-related stigma and discrimination in Ghana: experience of patients and their caregivers. Ghana medical journal, 49(1), 30-39. https://doi.org/10.4314/gmj.v49i1.6

Van der Geest, S. (2002). Respect and reciprocity: Care of elderly people in rural Ghana. Journal of cross-cultural gerontology, 17(1), 3-31.

World Health Organisation (2012). Supporting Informal Caregivers of People Living with Dementia.

Whitlatch, C. J., Zarit, S. H., \& von Eye, A. (1991). Efficacy of interventions with caregivers: a reanalysis. The Gerontologist, 31(1), 9-14. https://doi.org/10.1093/geront/31.1.9

Zarkowska, E., \& Clements, J. (2018). Problem behaviour and people with severe learning disabilities: the STAR approach: Routledge. https://doi.org/10.4324/9780429468209

\section{Copyright Disclaimer}

Copyright reserved by the author(s).

This article is an open-access article distributed under the terms and conditions of the Creative Commons Attribution license (http://creativecommons.org/licenses/by/3.0/). 